\title{
Colonic polyps in children and adolescents
}

\author{
Carol A Durno MSc MD FRCPC
}

\author{
CA Durno. Colonic polyps in children and adolescents. Can J \\ Gastroenterol 2007;21(4):233-239.
}

\begin{abstract}
Colonic polyps most commonly present with rectal bleeding in children. The isolated juvenile polyp is the most frequent kind of polyp identified in children. 'Juvenile' refers to the histological type of polyp and not the age of onset of the polyp. Adolescents and adults with multiple juvenile polyps are at a significant risk of intestinal cancer. The challenge for adult and pediatric gastroenterologists is determining the precise risk of colorectal cancer in patients with juvenile polyposis syndrome. Attenuated familial adenamatous polyposis (AFAP) can occur either by a mutation at the extreme ends of the adenomatous polyposis coli gene or by biallelic mutations in the mut $\mathrm{Y}$ homologue $(\mathrm{MYH})$ gene. The identification of $\mathrm{MYH}$-associated polyposis as an autosomal recessive condition has important implications for screening and management strategies. Adult and pediatric gastroenterologists need to be aware of the underlying inheritance patterns of polyposis syndromes so that patients and their families can be adequately evaluated and managed. Colonic polyps, including isolated juvenile polyps, juvenile polyposis syndrome, FAP, AFAP and $\mathrm{MYH}$-associated polyposis, are discussed in the present review.
\end{abstract}

Key Words: Familial adenamatous polyposis; Juvenile polyp; Juvenile polyposis syndrome; MYH-associated polyposis

$\mathrm{C}_{\mathrm{i}}^{\mathrm{i}}$ rolonic polyps most commonly present with rectal bleeding in children. The majority of polyp lesions identified during childhood are almost always benign. Some children and adolescents with polyps have an underlying predisposition to develop colorectal cancer (CRC). Pediatric patients with colonic polyps often do not have a fully developed polyposis phenotype, making identification of those at risk of CRC a challenge. In general, determining the actual risk of CRC for the individual patient can be difficult. However, in adults, the decision to use genetic testing is often more straightforward if the patient exhibits a characteristic polyposis syndrome. Recently, much progress has been made in the understanding of the genetic etiology of familial polyposis syndromes. Genetic testing to confirm diagnosis and to test asymptomatic relatives has become a part of standard care for persons and families with these conditions. The identification of a polyposis syndrome in offspring may have major implications for parents. Adult and pediatric gastroenterologists need to be aware of the underlying inheritance patterns of polyposis syndromes so that patients and their families can be adequately evaluated and managed. Colonic polyps, including isolated juvenile

\section{Polypes du côlon chez les enfants et les adolescents}

Les polypes du côlon se manifestent le plus fréquemment par des saignements rectaux chez les enfants. Le polype juvénile isolé est le type de polype le plus souvent observé chez les enfants. Précisons qu'ici, le terme « juvénile » fait référence au type histologique du polype et non à l'âge du patient au moment de son développement. Les adolescents et les adultes qui présentent des polypes juvéniles multiples sont exposés à un risque important de cancer de l'intestin. Le défi, pour les gastro-entérologues qui œuvrent auprès des adultes et des enfants est de déterminer le risque précis de cancer colorectal chez les patients atteints du syndrome de polypose juvénile. La polypose adénomateuse familiale (PAF) atténuée peut apparaître à la suite d'une mutation aux dernières extrémités du gène de la polypose colique adénomateuse ou à la suite de mutations des deux allèles du gène mutY homologue (MYH). L'identification d'une polypose associée au MYH comme maladie autosomique récessive a d'importantes répercussions sur les stratégies de dépistage et de prise en charge. Les gastroentérologues auprès des adultes et des enfants doivent être au courant des modes de transmission héréditaire sous-jacents des syndromes de polypose pour que les patients et leurs familles soient adéquatement évalués et traités. Les polypes du côlon, y compris les polypes juvéniles isolés, le syndrome de polypose juvénile, la PAF, la PAF atténuée et la polypose associée au MYH, sont abordés dans la présente synthèse.

polyps, juvenile polyposis syndrome (JPS), familial adenomatous polyposis (FAP), attenuated familial adenomatous polyposis (AFAP) and mut $\mathrm{Y}$ homologue (MYH)-associated polyposis (MAP), are discussed in the present review.

\section{JUVENILE POLYP}

The most common type of polyp encountered in pediatric gastroenterology is the isolated juvenile polyp (1). The term 'juvenile' refers to the type of polyp and not the age of onset of the polyp. The most frequent presentation is painless rectal bleeding. Other presentations include a prolapsing rectal mass (Figure 1) (frequently mislabelled as a rectal prolapse) or mucopurulent stools. Juvenile polyps are most frequently diagnosed in the first 10 years of life, with a peak age of diagnosis between two and five years of age.

Approximately $50 \%$ of children with juvenile polyps have more than one polyp, with the majority being left sided. Polyps measure $1 \mathrm{~cm}$ to $3 \mathrm{~cm}$ in size, with $90 \%$ being pedunculated (Figure 2). Histologically, the typical juvenile polyp has a distinctive cystic architecture, mucus-filled glands, a prominent lamina propria and dense infiltration with inflammatory

Familial Gastrointestinal Cancer Registry and Department of Surgery, Mount Sinai Hospital; Division of Gastroenterology, Hepatology and

Nutrition, Department of Paediatrics, The Hospital for Sick Children, University of Toronto, Toronto, Ontario

Correspondence: Dr Carol A Durno, The Hospital for Sick Children, Division of Gastroenterology and Nutrition, 555 University Avenue,

Toronto, Ontario M5G 1X8. Telephone 416-281-7476, fax 416-281-7313, e-mail carol.durno@sickkids.ca

Received and accepted for publication June 21, 2006 


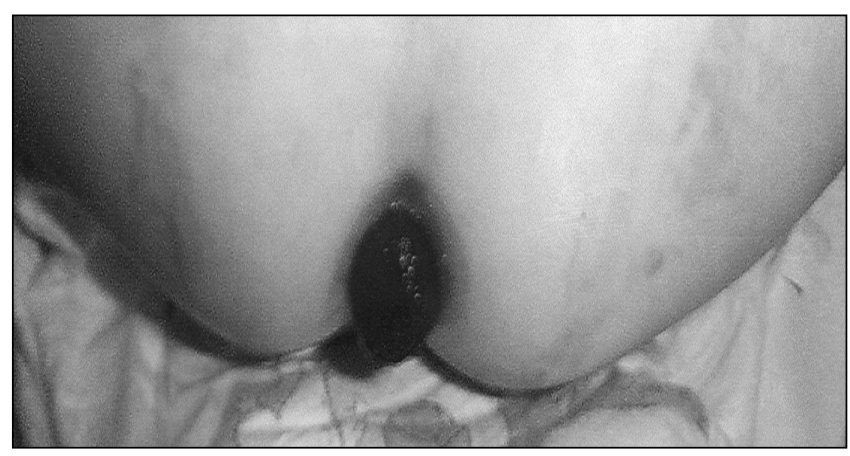

Figure 1) Two-year-old boy presenting with a 'prolapsing mass'. Colonoscopy revealed an isolated juvenile polyp which was removed by snare polypectomy. Histology confirmed a juvenile polyp

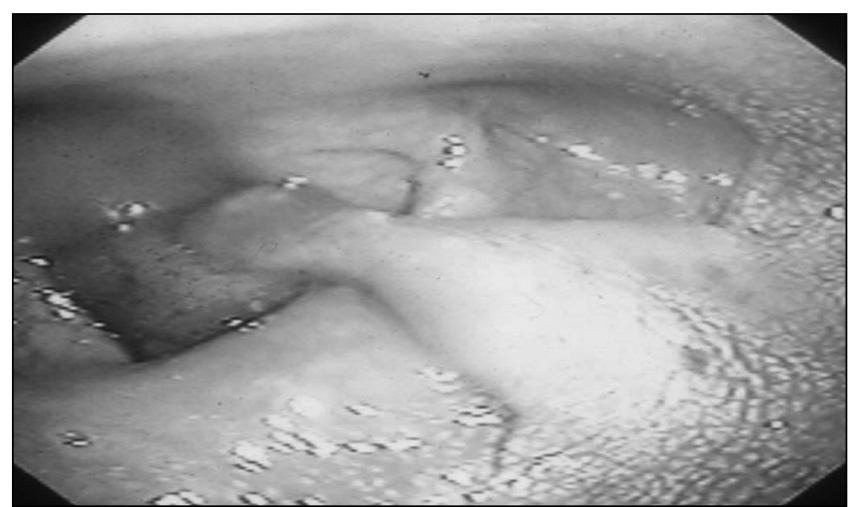

Figure 2) A pedunculated juvenile polyp on a long stalk identified in the sigmoid colon of a five-year-old girl presenting with a one-year history of intermittent, painless rectal bleeding

cells. These findings have led to overlapping terminology, including inflammatory polyps, retention polyps and hyperplastic polyps, depending on the dominant histological finding.

Solitary juvenile polyps carry no risk of intestinal cancer (2). The number of juvenile polyps is important because more than five polyps may carry implications for risk of CRC, which is discussed below. A challenge occurs when managing a patient with three or four juvenile polyps, because it is unclear whether the patient will develop the JPS phenotype (3) and therefore be at significant risk of intestinal cancer.

Colonoscopy with snare polypectomy and histological review is sufficient for management of isolated juvenile polyps. When there is a family history of juvenile polyps or when multiple polyps are found, the possibility of JPS is raised and a different management strategy is necessary.

\section{JPS}

JPS is an autosomal dominant condition characterized by multiple (more than five) juvenile polyps throughout the colon (4). Gastroenterologists should clinically suspect JPS when there are multiple juvenile polyps in the colon, or when juvenile polyps are found outside the colon. The polyps are mostly found in the colon but may occur throughout the gastrointestinal (GI) tract. Patients usually present late in childhood or in early adolescence with rectal bleeding. The polyps continue to accumulate during adulthood. In very rare cases, children (including infants) present with failure to thrive,
TABLE 1

Colonic polyps in children

\begin{tabular}{lll}
\hline Syndrome & Gene defect & Histology \\
\hline Juvenile polyp & Unknown & Hamartoma \\
Juvenile polyposis syndrome & SMAD4; BMPR1A & Hamartoma \\
FAP & $A P C$ & Adenoma \\
AFAP & $A P C ; M Y H$ & Adenoma \\
MAP & $M Y H$ & Adenoma \\
\hline
\end{tabular}

AFAP Attenuated Familial adenamatous polyposis; APC Adenomatous polyposis coli; MAP mut $Y$ homologue (MYH)-associated polyposis

anemia, hypoalbuminemia and abdominal pain secondary to large numbers of polyps throughout the GI tract. The histology of the polyps is characteristic of typical juvenile polyps as described above.

Investigators have tried to classify patients with multiple juvenile polyps into subgroups based on clinical presentation, with a diagnosis of either generalized juvenile polyposis (polyps throughout the GI tract), juvenile polyposis coli (polyps limited to the colon) and familial juvenile polyposis (juvenile polyps and a family history). When a patient has more than five juvenile polyps of the colorectum, juvenile polyps throughout the GI tract, or any number of juvenile polyps and a family history of juvenile polyposis (5), a JPS diagnosis should be considered.

Determining the precise cancer risk in children and adults with juvenile polyposis is a challenge. Family studies of juvenile polyposis suggest a $50 \%$ risk of developing GI cancer (5-7). CRC has been diagnosed in patients with juvenile polyposis as young as four years of age, although the mean age is in the third decade of life (6). The challenge is determining the risk of CRC in isolated individuals with multiple polyps (8). Genetic mutations, including SMAD4 (a transforming growth factor-beta intracellular signalling molecule) or BMPR1A, have been identified in $40 \%$ to $60 \%$ of patients with juvenile polyposis $(4,9)$ (Table 1$)$. An inactivating mutation in SMAD4 results in unopposed growth and polyp formation (Figure 3) (1). The mutant SMAD4 sequence predicts a truncated protein and absence of domains that are required for normal cellular functioning. Approximately $25 \%$ of newly diagnosed patients with JPS appear to have de novo or new mutations, with $75 \%$ exhibiting a family history (10).

Molecular genetic diagnosis may offer better predictors of cancer risk in children and adults with juvenile polyps. It is important for adult gastroenterologists following patients with juvenile polyposis to communicate that their offspring may be at risk of developing polyposis and subsequent GI cancer. Offspring presenting in their early teens or when symptoms occur should be considered for genetic testing when the disease-causing mutation is known in the family. Suggested surveillance includes colonoscopy every three years from the time of symptom occurence or in the early teen years if symptoms have not occurred in the setting of a family history, and upper endoscopy every two years beginning at 15 years of age (4).

\section{FAP}

The majority of children and adolescents who are evaluated for FAP are identified in the context of a positive family history of FAP. This is because patients generally do not develop GI 


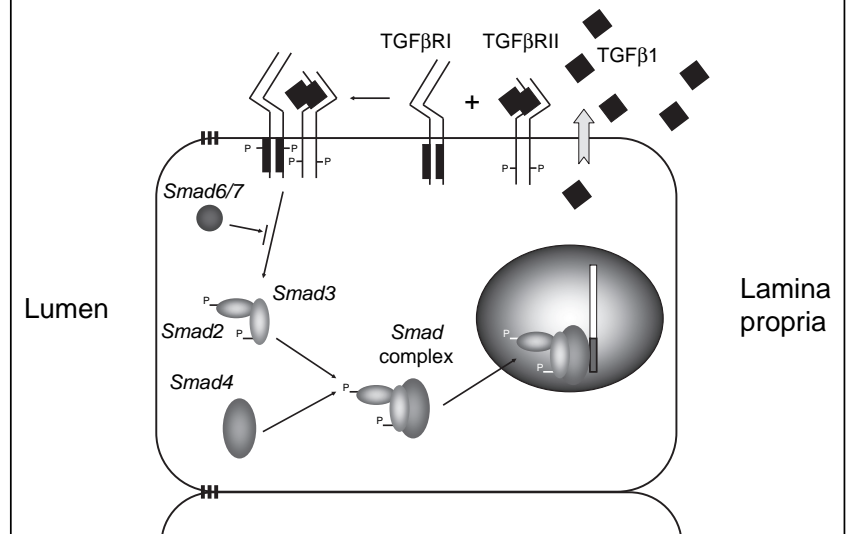

Figure 3) Interruption of growth inhibitory signalling by a transforming growth factor-beta (TGF- $\beta$ ) by mutant Smad4. TGF- $\beta$ signalling normally initiates cell cycle arrest and growth inhibition. In some kindreds with juvenile polyposis, a germline mutation in the TGF- $\beta$ signalling protein, Smad4, interrupts growth inhibitory signalling by TGF- $\beta$, the result being unopposed growth and polyp formation. TGF- $\beta$ RI/RII Transforming growth factor-beta receptor 1 / receptor 2 . Reproduced/adapted with permission from Dr John Barnard, Children's Research Institute (Ohio, USA)

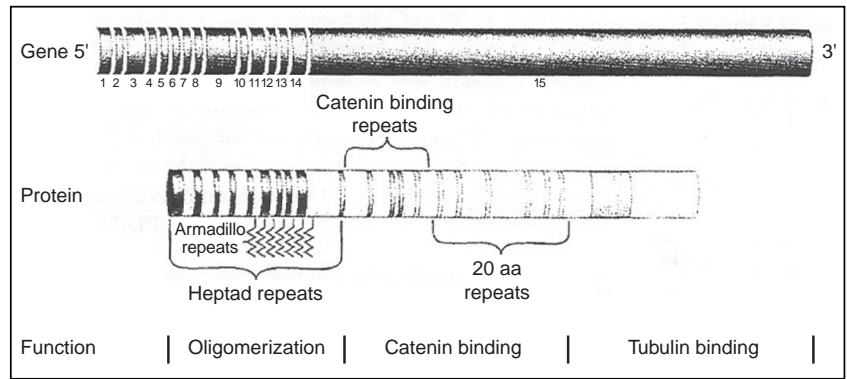

Figure 4) The anatomy of the adenomatous polyposis coli gene and its protein. Reproduced/adapted with permission from reference 46

symptoms until the third decade of life (mean age 33 years). Approximately $20 \%$ to $30 \%$ of FAP patients without a family history of the disease appear to have 'new mutations'. Thus, parents and siblings are not found to have the disease on investigation, but children of the affected person are at a 50\% risk of the condition. The adenomatous polyposis coli (APC) gene is a large gene located on the long arm of chromosome 5 (Figure 4). The APC gene produces a large (2843 amino acids, $312 \mathrm{kDa})$ APC protein. Over 730 germline mutations have been identified; most of these are nonsense or frameshift mutations that result in a premature stop codon, thus producing a truncated, inactive APC protein. Current clinical screening recommendations for all first-degree relatives of patients with FAP include annual sigmoidoscopy beginning at 10 to 12 years of age (11). Most children with FAP have no GI symptoms. However, there are young children who present with hematochezia who have no family history of FAP and who are found to have a severe FAP phenotype (defined as greater than 1000 polyps) (12). Extracolonic tumours, both benign and malignant, can also occur, including hepatoblastoma, cystic osteomas of the jaw, desmoid tumours and multiple sebaceous cysts.

The link among hepatoblastoma, FAP, APC mutations and congenital hypertrophy of the retinal pigment epithelium is

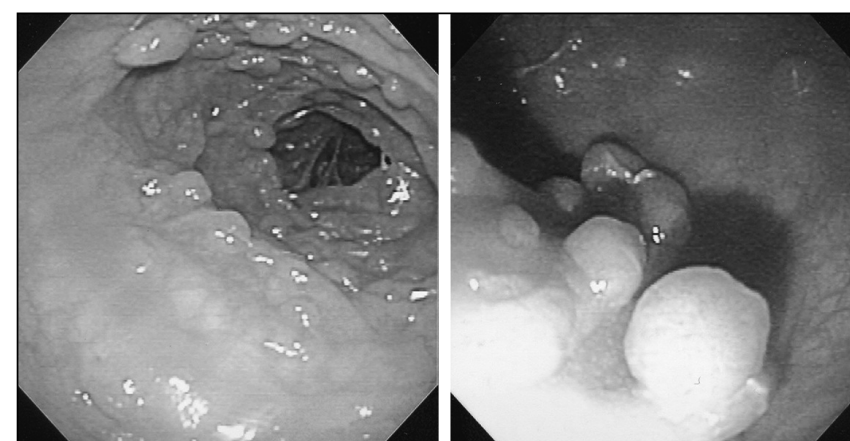

Figure 5) Multiple adenomatous polyps identified at sigmoidoscopy in a 15-year-old boy being screened for familial adenomatous polyposis due to a maternal familial adenomatous polyposis history

well established (13-17) The incidence of FAP in hepatoblastoma patients is approximately 100 times that in the general population. A major function of the APC gene is the downregulation of beta-catenin, a transcription-activating protein with oncogenic potential. APC mutations can alter this 'tumour suppressor' function, leading to an increased risk of hepatic malignancy and hepatoblastoma in particular (13). Hepatoblastomas typically affect children younger than three years of age and are the most common malignant liver tumours in children. Familial hepatoblastoma (siblings affected with hepatoblastoma) should raise the suspicion of an inherited APC mutation, warranting screening of parents for FAP (ophthalmological examination, colonoscopy and consideration of molecular studies). Sporadic hepatoblastoma appears to be associated with germline, rather than genomic APC mutations, in non-FAP families (13). Currently, no hepatoblastoma evidence-based screening guidelines are recommended for families with FAP.

This autosomal dominant disorder leads to the development of hundreds to thousands of adenomatous polyps in the colon (Figure 5). The average age of adenoma appearance is 16 years and the average age of colon cancer appearance is 39 years (10). Virtually all patients with FAP develop adenocarcinoma of the colon or rectum if left untreated, and therefore, prophylactic colectomy is the standard of care. However, the timing of the colectomy is challenging and somewhat controversial. What is the risk of malignancy for the individually affected child? Peck et al (18) reviewed the available literature and identified 10 cases of cancer in FAP patients younger than 20 years of age. The youngest patient was five years old. Church et al (19) surveyed polyposis registries around the world to assess risk of CRC in children and teenagers with FAP. Among the 16 registries that responded, 14 patients younger than 20 years of age were identified with CRC. The youngest was nine years old. Nine of the 14 young patients with CRC had severe polyposis (defined as greater than 1000 colonic polyps) and one had mild polyposis. Church et al (19) calculated an estimated incidence of one case of CRC per 471 affected FAP patients younger than 20 years of age. However, gene mutations were not included in this study. Genotyping would have been interesting, because mutations in exon 15G classically result in a severe phenotype, which makes identification of these mutations relevant to patient management (20). In summary, cancer rarely occurs in FAP patients younger than 20 years of age and is usually associated with a severe polyposis phenotype. 
TABLE 2

\begin{tabular}{lc}
$\begin{array}{l}\text { Spigelman staging of duodenal polyposis in familial } \\
\text { adenamatous polyposis }\end{array}$ & Points \\
\hline Polyp number & 1 \\
\hline $1-4$ & 2 \\
$5-20$ & 3 \\
$>20$ & \\
Histological type & 1 \\
\hline Tubular polyp/hyperplasia/inflammation & 2 \\
Tubulovillous & \\
Dysplasia & 1 \\
$\quad$ Mild & 2 \\
$\quad$ Moderate & 3 \\
Severe & \\
Stages & 0 \\
\hline 0 & $1-4$ \\
I & $5-6$ \\
II & $7-8$ \\
III & $9-12$ \\
IV &
\end{tabular}

Reproduced/adapted from reference 47

FAP, in $90 \%$ of families, arises from mutations of the APC gene (21). There is some correlation between the location of the mutation in the APC gene and the clinical phenotype of FAP (21,22). Extreme polyposis is observed when mutations are in the midportion of exon 15 (the central portion of the gene). Desmoid tumours and osteomas are more common with mutations in the distal portion of the gene (21).

Adenomatous duodenal polyps are common in FAP, with rates approaching $100 \%$ in patients who were followed over time (23-25). However, only a small fraction of affected patients develop invasive cancer ( $3 \%$ to $5 \%$ ), because the progression of neoplasia in the duodenum of patients with FAP is slow $(23,24)$. As a result, there is little evidence to support the initiation of upper GI surveillance in young children or adolescents with FAP (26). Current screening recommendations include upper endoscopy starting from 25 or 30 years of age (23), with the subsequent screening interval determined by the stage at baseline (27). Most FAP registries screen all FAP and attenuated FAP adults for duodenal adenomas, with aggressive interventional endoscopy at one- to five-year intervals (based on the Spigelman stage [Table 2]) and surgical resection reserved for severe cases (28).

Cyclooxygenase-2 inhibitors have shown promise in managing polyp burden in adult patients with FAP (29). During the development of a phase III pediatric trial of celecoxib and FAP, cardiovascular side effects were reported. Consequently, Health Canada removed FAP as an indication for celecoxib in December 2004, and thus, the drug is no longer available. Interestingly, no other country has followed suit.

\footnotetext{
AFAP

AFAP is a variant of FAP. Several distinct mutations within the APC gene have been associated with an attenuated phenotype and an autosomal dominant pattern of inheritance. Patients present with fewer colorectal polyps (less than 100, average 30), later onset of polyps and cancer, extracolonic manifestations and a predilection toward involvement of the
}

proximal colon. Variability of phenotype expression within kindreds with identical mutations makes classification difficult (30). To date, at least 34 distinct mutations have been identified within the APC gene locus in individuals manifesting the attenuated FAP phenotype (31). Depending on the specific location of attenuated FAP mutation, varying phenotypic expression has been noted. Mutations at the $3^{\prime}$ end of the APC gene and within exon 9 are associated with fewer adenomas, whereas those at the $5^{\prime}$ end result in a more variable number of colorectal adenoma, and more severe upper GI manifestations (27).

Clinical surveillance in patients with AFAP may be based on the results of genetic testing. In individuals who test positive for a mutation associated with AFAP, baseline colonoscopy is recommended for those between 16 and 18 years of age (11). Early endoscopy is recommended due to the phenotypic variability seen within kindreds possessing identical mutations and the potential consequences of missing an early age of onset leading to a more profuse polyposis phenotype. Screening with flexible sigmoidoscopy, the recommended modality for classic FAP (11), is inadequate because of the preponderance of right-sided lesions in AFAP. Patients with an APC mutation but negative endoscopic examination should undergo a repeat colonoscopy at 20 years of age. Patients who have colonoscopic findings consistent with AFAP should undergo polypectomy when feasible, followed by continued yearly surveillance.

Colectomy is advised when polyps are difficult to control colonoscopically (20 polyps or more; when one or more polyps show advanced characteristics, including size larger than $1 \mathrm{~cm}$; or advanced histology). For patients with uninformative test results, the same recommendations apply, except that subsequent colonoscopy may be performed at two-year intervals. Upper endoscopy screening recommendations for AFAP are the same as for FAP and include upper endoscopy starting from 25 or 30 years of age (23).

Genetic testing for APC mutations should be considered in persons who exhibit typical FAP and also in persons with as few as 10 adenomas because of the possibility of AFAP (30). AFAP is not a distinct clinical entity and is a piece of the larger puzzle in the genetic predisposition to CRC (26). Large genotype-phenotype studies will help identify AFAP patients at greatest risk of CRC. Recent attention has focused on characterizing genetic predisposition to AFAP in individuals who do not have germline mutations in the APC gene.

\section{MAP}

Until recently, no other genetic causes had been described for the remainder of patients with FAP or AFAP. A second mechanistic explanation called MAP, an autosomal recessive condition, has been identified which has important implications for both screening and management strategies. In 2002, Al-Tassan et al (32) reported a family with recessive inheritance of multiple colorectal adenomatous polyps and carcinoma in three affected members of a single sibship. Until Al-Tassan's discovery, no inherited defects of base excision repair had been associated with any human genetic disorder. Mutations of the genes mutM and mutY, which function in Escherichia coli base excision repair, led to increased transversions of guanine : cytosine to thiamine : adenine (33). Analysis of the human homologue of mutY, MYH, identified two missense variants - Y165C and G382D - in the affected subjects, 
while unaffected siblings and the parents carried either heterozygous mutations or wild-type MYH sequences. APC mutations are detected in approximately $60 \%$ to $80 \%$ of classic FAP patients and in $10 \%$ to $30 \%$ of AFAP patients; MYH mutations are likely to account for about $10 \%$ and $20 \%$ to $25 \%$ of patients in these groups, respectively $(34,35)$.

Genetic analysis of MYH should be offered to patients younger than 18 years of age with a phenotype resembling FAP or AFAP when no APC mutation is identified by genetic testing. Predictive genetic testing should be offered to siblings of patients found to have biallelic mutations to assess the need for endoscopic surveillance starting at 21 years of age. The current approach to children of biallelic carriers includes full gene screening of unaffected spouses to rule out heterozygous (or even asymptomatic biallelic) carriers, which may result in transmission of a biallelic state to offspring.

What is the significance of MYH mutations for children and adolescents? Sampson et al (36) studied 614 families with either presumptive or genetically confirmed FAP or AFAP in polyposis registries in the United Kingdom. The youngest case identified among the 25 patients with biallelic mutations of the MYH gene was a 13-year-old boy. This adolescent had more than 100 polyps and carried the two common MYH mutations (Y165C/G382D). This boy went on to develop gastric cancer at 17 years of age, suggesting the possibility of additional causative factors. This teenager is the youngest patient described with polyps and MYH biallelic mutations (36). The youngest MAP patient with CRC was a 21-year-old woman with 36 colonic polyps (37).

At Mount Sinai Hospital (Toronto, Ontario), we have screened five patients younger than 24 years of age presenting with CRC who had no detectable APC or hereditary nonpolyposis CRC mutations identified (38). No MYH mutations were identified. Thus, it appears that MYH mutations are not a common cause of multiple polyps in those presenting before 30 years of age. However, it must also be understood that to date, few patients younger than 18 years of age and diagnosed with adenomatous polyps or CRC have been screened for MYH mutations.

What is the management strategy for children and adolescents of parents with biallelic MYH mutations? Using statistical predictions, a carrier of two MYH mutations rarely produces children with a partner who also carries a heterozygous mutation (incidence of $1 \%$ to $2 \%$ of heterozygous MYH mutations in Caucasians) (39). In this case, the polyposis appears to be dominantly inherited in the offspring. Whether it makes sense to undertake genetic testing of the partners of patients with biallelic MYH mutations remains unclear. It will be of interest to evaluate teenagers and young adults with previously presumed AFAP for MYH mutations to determine the MYH phenotype, including the age of onset of polyposis along with the risk of adenomatous polyps and carcinoma. Furthermore, larger studies including adolescents and adults are necessary to help piece together the emerging MYH puzzle.

Most data on MYH suggest that the age at onset of polyposis is seen at a later stage in classic FAP, so initiating surveillance after 21 years of age seems reasonable (40). Further studies are required to assess the natural history of colorectal neoplasia in patients with MAP to guide surveillance intervals in adults and to make decisions regarding the timing of surgical interventions. While such studies are underway, most experts suggest that the clinical management of patients with biallelic mutations in MYH should be the same as for individuals with classic FAP.

As MYH screening becomes more widely available, pediatric gastroenterologists will be referred adolescents with MYH mutations identified as part of the evaluation of their affected parents. Adolescents with one MYH mutation do not require augmented screening colonoscopy (38). For children and teenagers found to have biallelic MYH mutations, who were tested based on their parents or siblings, MYH status does not require upper endoscopy and colonoscopy until 21 years of age (40). As prospective studies are completed, the precise lifetime risk of adenomatous polyps and CRC will be determined for obligate carriers.

\section{GENETIC COUNSELLING}

The importance of a thorough and accurate family history cannot be overstated. In most practices, a genetics consultation is probably necessary to assure collection of a sufficiently detailed family history and to assure that active efforts are made to collect relevant family medical records to verify verbal reports. The content of a genetics consultation provides the groundwork for any genetic testing that may eventually be offered (8). Because of the intensity and specialized nature of a genetic risk assessment, most physicians rely on a specialized centre with a multidisciplinary team.

The aim of polyposis registries is to promote the identification of relatives at risk of CRC and to ensure lifelong participation in surveillence programs. Another benefit of affiliation with a registry is access to specialty services such as prenatal counselling and support groups. Registries offer options for patient education, such as information pamphlets, and other age-appropriate visual aids (the registry at Mount Sinai Hospital has developed a child and adolescent friendly section, titled "Kids' Korner", on the registry Web site $<$ www.mtsinai.on.ca/familialgicancer>), which are useful adjuncts to genetic counselling. The decision to involve a child in the preparatory session is age- and maturity-dependent. Ideally, adolescents should be involved in the preparatory session so that they clearly understand the purpose and implications of genetic testing. Genetic counselling must also include an exploration of specific issues related to the family history and experiences with FAP (41). This may involve close personal involvement with relatives who have had cancer, variable screening experiences or surgical procedures. Family relationships can be profoundly affected by issues such as guilt and blame, and personal and familial identity may be strongly linked to FAP status. It is important to explore the perception of risk and its meaning, as well as the anticipated meaning of any test results. An essential task should be to determine whether the child has any psychologically damaging misperceptions regarding what having FAP and genetic testing itself means. The possibility of uninformative kindred testing, as well as the psychological implications for the patient and family, need to be discussed. Parents of at-risk minor children should devote time to discuss how and when test results and risks are to be communicated to the children.

Predictive genetic testing is now widely available for FAP and many FAP registries have adopted a policy of offering genetic testing at the onset of endoscopic screening. Genetic testing usually begins with an affected relative. The diseaseproducing mutation can be identified in approximately $80 \%$ of kindreds. Once the mutation is found in a person known to 
have FAP, other at-risk family members can be tested for the presence or absence of the same mutation with approximately $100 \%$ accuracy (3). If the child is not found to carry the mutation, no clinical screening is required, although the child is, of course, still at the same risk of CRC as the general population. When genetic testing for the APC mutation in a family is uninformative (20\% of cases), all at-risk relatives require endoscopic surveillance (11) beginning at 10 to 12 years of age. A survey involving 177 individuals tested for an APC mutation revealed that nearly one-third of uninformative genetic tests were misinterpreted by clinicians as a negative test result (42). Therefore, FAP families are best counselled and managed at specialty centres or by physicians with adequate education regarding the genetics of FAP.

\section{COMPLIANCE WITH SURVEILLANCE}

Many adolescents perceive bowel examination as an invasive procedure, and they may not comply with surveillance protocols. For parents, this process may reinforce latent fears, as indicated in a FAP adaptation study in which many parents expressed guilt about transmitting the mutant APC gene to their offspring (43). Parent information gaps or misperceptions may be mirrored in their offspring. Many children and adolescents benefit from a child-focused approach involving social workers, play therapists and specialized nurses experienced with issues related to FAP.

Many centres provide endoscopy in a pediatric endoscopy unit. This has helped to ensure that early screening experiences are seen in a positive manner because the subsequent annual

\section{REFERENCES}

1. Corredor J, Wambach J, Barnard J. Gastrointestinal polyps in children: Advances in molecular genetics, diagnosis, and management. J Pediatr 2001;138:621-8.

2. Nugent KP, Talbot IC, Hodgson SV, Phillips RK. Solitary juvenile polyps: Not a marker for subsequent malignancy. Gastroenterology 1993;105:698-700.

3. Burt R, Neklason DW. Genetic testing for inherited colon cancer. Gastroenterology 2005;128:1696-716.

4. Schreibman IR, Baker M, Amos C, McGarrity TJ.

The hamartomatous polyposis syndromes: A clinical and molecular review. Am J Gastroenterol 2005;100:476-90.

5. Jass JR, Williams CB, Bussey HJ, Morson BC. Juvenile polyposis - a precancerous condition. Histopathology 1988;13:619-30.

6. Giardiello FM, Hamilton SR, Kern SE, et al. Colorectal neoplasia in juvenile polyposis or juvenile polyps. Arch Dis Child 1991;66:971-5.

7. Howe JR, Mitros FA, Summers RW. The risk of gastrointestinal carcinoma in familial juvenile polyposis. Ann Surg Oncol 1998;5:751-6.

8. Lindor NM. Recognition of genetic syndromes in families with suspected hereditary colon cancer syndromes. Clin Gastroenterol Hepatol 2004;2:366-75.

9. Howe JR, Sayed MG, Ahmed AF, et al. The prevalence of MADH4 and BMPR1A mutations in juvenile polyposis and absence of BMPR2, BMPR1B, and ACVR1 mutations. J Med Genet 2004;41:484-91.

10. GeneTests. <http:/GENETests.org > (Version current at November 9, 2006).

11. Leddin D, Hunt R, Champion M, et al; Canadian Association of Gastroenterology; Canadian Digestive Health Foundation. Canadian Association of Gastroenterology and the Canadian Digestive Health Foundation: Guidelines on colon cancer screening. Can J Gastroenterol 2004;18:93-9.

12. Auricchio R, De Rosa M, Quaglietta L, et al. A dramatic case of early-onset familial adenomatous polyposis. Clin Genet 2005;67:104-6. examination is dependent on voluntary participation (44). We give adolescents and children some control by being encouraged to decide on their bowel preparation, choice of initial intravenous (propofol sedation or gas via mask sedation) and time of year that best suits their schedule for the endoscopy. It is important not to be zealous with overscreening of children and adolescents, because this may affect long-term compliance and trust in the health care system.

\section{FUTURE DIRECTIONS}

The majority of colonic polyps encountered in children and adolescents are benign lesions that are not associated with an underlying polyposis syndrome or risk of CRC. The challenge is identifying those patients who are developing a polyposis syndrome phenotype and therefore are at risk of CRC.

AFAP can occur either by a mutation at the extreme ends of the APC gene or by biallelic mutations in the MYH gene. The identification of MAP, as an autosomal recessive condition has important implications for screening and management strategies. Molecular genetic diagnosis and the discovery of mechanisms underlying polyp predisposition will allow for the development of more precise criteria for determining cancer risk in children and adults with multiple juvenile polyps (45). Adult and pediatric gastroenterologists need to be aware of the underlying inheritance patterns of polyposis syndromes so that patients and their families can be adequately evaluated and managed. Unquestionably, the future will bring the discovery of new genes that cause polyposis syndromes and contribute to the risk of developing cancer.

13. Thomas D, Pritchard J, Davidson R, McKiernan P, Grundy RG, de Ville de Goyet J. Familial hepatoblastoma and APC gene mutations: Renewed call for molecular research. Eur J Cancer 2003;39:2200-4.

14. Hughes LJ, Michels VV. Risk of hepatoblastoma in familial adenomatous polyposis. Am J Med Genet 1992;43:1023-5.

15. Kingston JE, Herbert A, Draper GJ, Mann JR. Association between hepatoblastoma and polyposis coli. Arch Dis Child 1983;58:959-62.

16. Bernstein IT, Bulow S, Mauritzen K. Hepatoblastoma in two cousins in a family with adenomatous polyposis. Report of two cases. Dis Colon Rectum 1992;35:373-4.

17. Garber JE, Li FP, Kingston JE, et al. Hepatoblastoma and familial adenomatous polyposis. J Natl Cancer Inst 1988;80:1626-8. (Erratum in 1989;81:461).

18. Peck DA, Watanabe KS, Trueblood HW. Familial polyposis in children. Dis Colon Rectum 1972;15:23-9.

19. Church JM, McGannon E, Burke C, Clark B. Teenagers with familial adenomatous polyposis: What is their risk for colorectal cancer? Dis Colon Rectum 2002:45:887-9.

20. Wu JS, Paul P, McGannon EA, Church JM. APC genotype, polyp number, and surgical options in familial adenomatous polyposis. Ann Surg 1998;227:57-62.

21. Burt RW, Jacoby RF. Polyposis syndromes. In: Yamada T, ed. Textbook of Gastroenterology, 4th edn. New York: Lippincott Williams \& Wilkins, 2003:1914-39.

22. Lipton L, Halford SE, Johnson V, et al. Carcinogenesis in $\mathrm{MYH}$-associated polyposis follows a distinct genetic pathway. Cancer Res 2003;63:7595-9.

23. Bulow S, Bjork J, Christensen IJ, et al; DAF Study Group. Duodenal adenomatosis in familial adenomatous polyposis. Gut 2004:53:381-6.

24. Heiskanen I, Kellokumpu I, Jarvinen H. Management of duodenal adenomas in 98 patients with familial adenomatous polyposis. Endoscopy 1999;31:412-16.

25. Bjork J, Akerbrant $\mathrm{H}$, Iselius L, et al. Periampullary adenomas and adenocarcinomas in familial adenomatous polyposis: Cumulative 
risks and APC gene mutations. Gastroenterology 2001;121:1127-35

26. Durno CA, Gallinger S. Genetic predisposition to colorectal cancer: New pieces in the pediatric puzzle. J Pediatr Gastroenterol Nutr 2006;43:5-15.

27. Groves CJ, Saunders BP, Spigelman AD, Phillips RK. Duodenal cancer in patients with familial adenomatous polyposis (FAP): Results of a 10 year prospective study. Gut 2002;50:636-41.

28. Moozar KL, Madlensky L, Berk T, Gallinger S. Slow progression of periampullary neoplasia in familial adenomatous polyposis. J Gastrointest Surg 2002;6:831-7.

29. Steinbach G, Lynch PM, Phillips RK, et al. The effect of celecoxib, a cyclooxygenase-2 inhibitor, in familial adenomatous polyposis. N Engl J Med 2000;342:1946-52.

30. Burt RW, Leppert MF, Slattery ML, et al. Genetic testing and phenotype in a large kindred with attenuated familial adenomatous polyposis. Gastroenterology 2004;127:444-51.

31. Hernegger GS, Moore HG, Guillem JG. Attenuated familial adenomatous polyposis: An evolving and poorly understood entity. Dis Colon Rectum 2002;45:127-34,134-6.

32. Al-Tassan N, Chmiel NH, Maynard J, et al. Inherited variants of MYH associated with somatic G:C->T:A mutations in colorectal tumors. Nat Genet 2002;30:227-32.

33. Slupska MM, Baikalov C, Luther WM, Chiang JH, Wei YF, Miller JH. Cloning and sequencing a human homolog $(h M Y H)$ of the Escherichia coli mutY gene whose function is required for the repair of oxidative DNA damage. J Bacteriol 1996;178:3885-92.

34. Powell SM, Petersen GM, Krush AJ, et al. Molecular diagnosis of familial adenomatous polyposis. N Engl J Med 1993;329:1982-7.

35. van der Luijt RB, Khan PM, Vasen HF, et al. Molecular analysis of the APC gene in 105 Dutch kindreds with familial adenomatous polyposis: 67 germline mutations identified by DGGE, PTT, and southern analysis. Hum Mutat 1997;9:7-16.

36. Sampson JR, Dolwani S, Jones S, et al. Autosomal recessive colorectal adenomatous polyposis due to inherited mutations of MYH. Lancet 2003;362:39-41.
37. Nielsen M, Franken PF, Reinards TH, et al. Multiplicity in polyp count and extracolonic manifestations in 40 Dutch patients with MYH associated polyposis coli (MAP). J Med Genet 2005;42:e54.

38. Durno C, Aronson M, Bapat B, Cohen Z, Gallinger S. Family history and molecular features of children, adolescents, and young adults with colorectal carcinoma. Gut 2005;54:1146-50.

39. Sieber OM, Lipton L, Crabtree M, et al. Multiple colorectal adenomas, classic adenomatous polyposis, and germ-line mutations in MYH. N Engl J Med 2003:348:791-9.

40. Wang L, Baudhuin LM, Boardman LA, et al. MYH mutations in patients with attenuated and classic polyposis and with young-onset colorectal cancer without polyps. Gastroenterology 2004;127:9-16. (Erratum in 2004;127:1651).

41. Petersen GM, Boyd PA. Gene tests and counseling for colorectal cancer risk: Lessons from familial polyposis. J Natl Cancer Inst Monogr 1995;17:67-71.

42. Giardiello FM, Brensinger JD, Petersen GM, et al. The use and interpretation of commercial APC gene testing for familial adenomatous polyposis. N Engl J Med 1997;336:823-7.

43. Miller HH, Bauman LJ, Friedman DR, DeCosse JJ. Psychosocial adjustment of familial polyposis patients and participation in a chemoprevention trial. Int J Psychiatry Med 1986-1987;16:211-30.

44. Burn J, Chapman PD, Eastham EJ. Familial adenomatous polyposis. Arch Dis Child 1994;71:103-5.

45. Gallione CJ, Repetto GM, Legius E, et al. A combined syndrome of juvenile polyposis and hereditary haemorrhagic telangiectasia associated with mutations in MADH4 (SMAD4). Lancet 2004;363:852-9.

46. Church JM. Anatomy of a gene: Functional correlations of APC mutation. Semin Colon Rectal Surg 1998;9:49-52.

47. Spigelman AD, Williams CB, Talbot IC, Domizio P, Phillips RK. Upper gastrointestinal cancer in patients with familial adenomatous polyposis. Lancet 1989;2:783-5. 


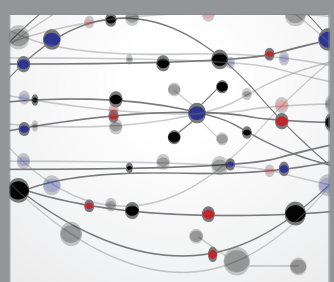

The Scientific World Journal
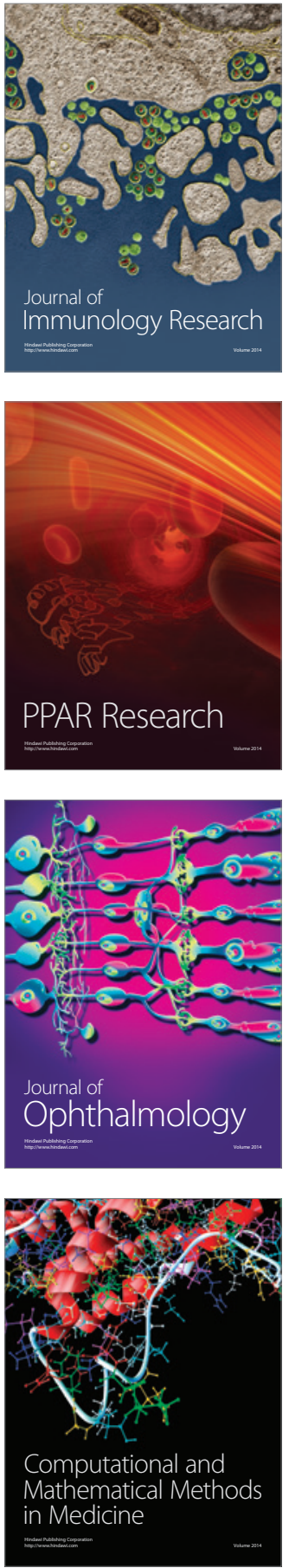

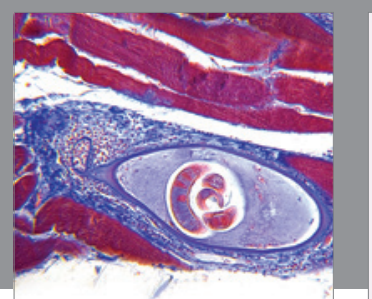

Gastroenterology Research and Practice

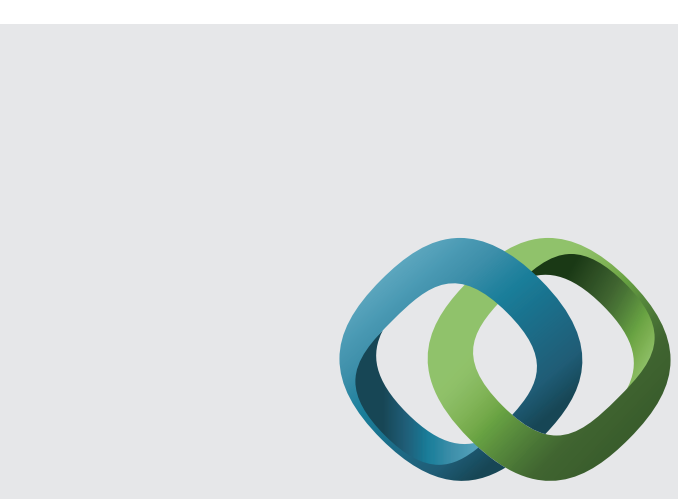

\section{Hindawi}

Submit your manuscripts at

http://www.hindawi.com
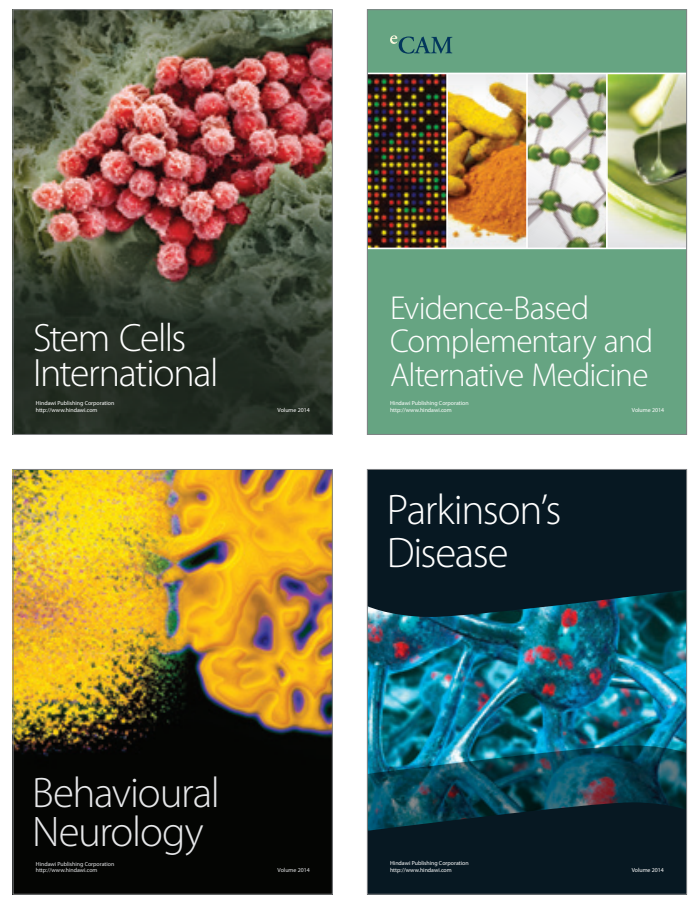
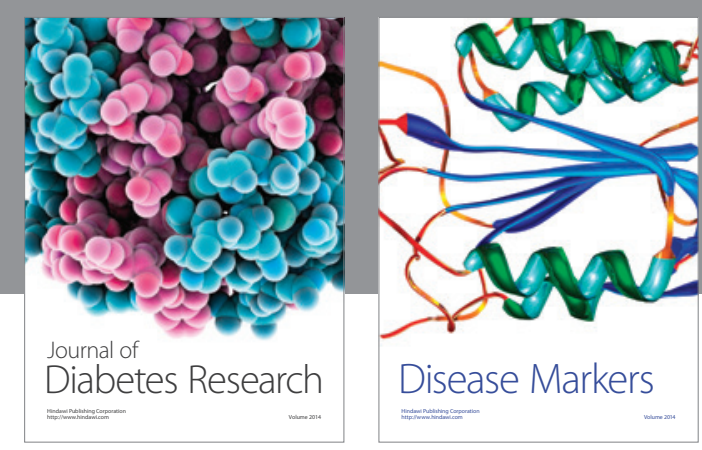

Disease Markers
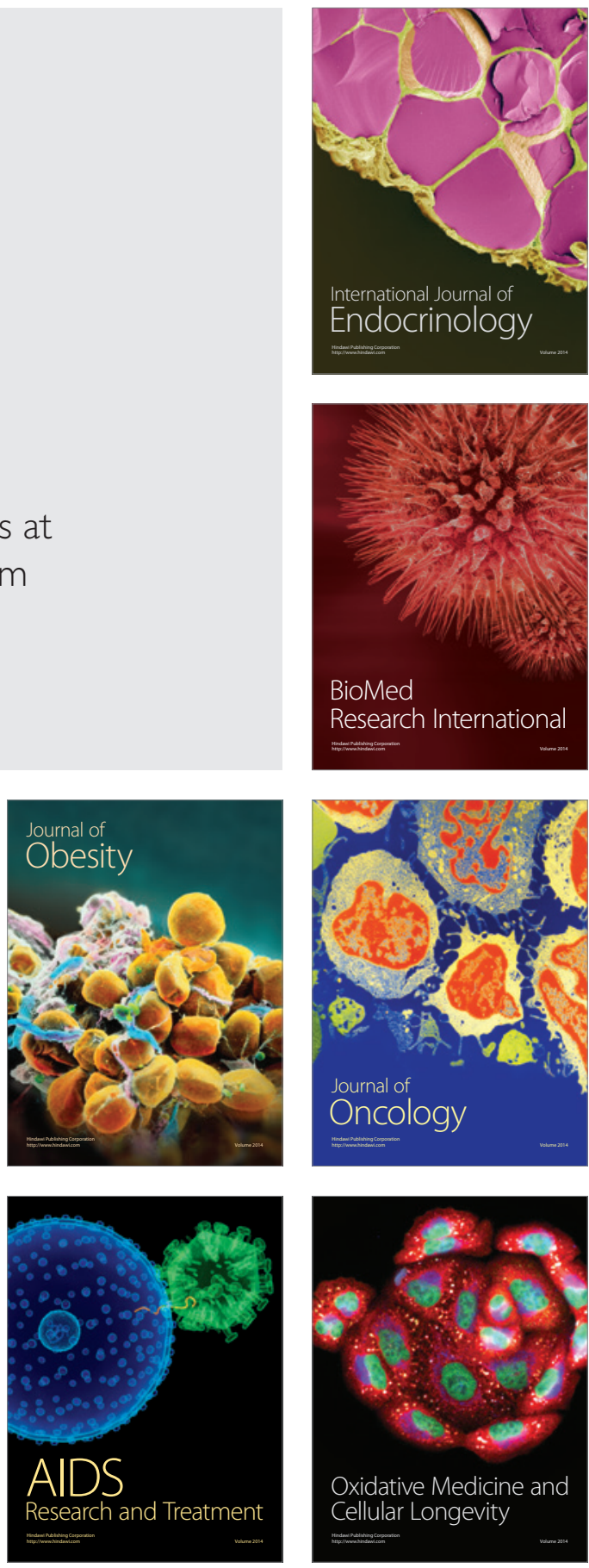